\title{
Patrones de residencia posmarital en la población prehistórica de Arica (Chile)
}

\author{
José A. Cocilovo, Héctor H. Varela y Silvia G. Valdano \\ 04 de enero 2021. 17 de agosto 2021
}

\begin{abstract}
RESUMEN
En las sociedades antiguas y actuales, se destaca la prevalencia de una estrategia de supervivencia basada en un sistema de parentesco con un modelo de residencia matrilocal. La población antigua de la costa y el valle de Azapa (Chile) brinda una oportunidad única para analizar las relaciones sociales y establecer el patrón de residencia posmarital y su evolución, sustentada por el desarrollo y adaptación de la población a los cambios producidos durante 5000 años. Para la realización del presente trabajo se empleó una muestra de 305 individuos de ambos sexos, exhumados en la costa y en el valle de Azapa, y de cinco períodos cronológicos establecidos por la arqueología. El estudio de 29 variables craneométricas se realizó empleando métodos de análisis discriminante, y la evaluación de la varianza dentro y entre grupos, a partir del estadístico Fst, por períodos y sexos. Los resultados obtenidos muestran la existencia de diferencias estadísticas significativas en los distintos ensayos realizados y una estructura social basada en un patrón de residencia bilocal, con transición a un modelo matrilocal.
\end{abstract}

Palabras clave: Arica; Estructura genética; Migraciones; Patrones de residencia posmarital.

\section{Post-marital residence patterns in the prehistoric population of Arica (Chile)}

\begin{abstract}
In ancient and living societies, the prevalence of a survival strategy based on a kinship system with a matrilocal residence model prevails. The ancient population of the Azapa valley and coast provides a unique opportunity to analyze social relationships and to establish the pattern of post-marital residence and its evolution supported by population development and adaptation to changes that occurred over a period of 5000 years. In this study, a sample of 305 individuals of both sexes exhumed from the coast and the Azapa valley regions, and belonging to five chronological periods established on the basis of archeological indicators, was investigated. Twenty-nine craniometric variables were analyzed through a discriminant function analysis and the evaluation of the variance within and between groups based on the Fst statistic by period and sex. The results obtained show the existence of significant statistical differences in the tests carried out, indicating a social structure based on a bilocal residence pattern transitioning to a matrilocal model.
\end{abstract}

Keywords: Arica; Genetic structure; Migrations; Post-marital residence patterns.

\footnotetext{
José A. Cocilovo. Instituto de Ciencias de la Tierra, Biodiversidad y Ambiente (ICBIA-CONICET), Departamento de Ciencias Naturales, Facultad de Ciencias Exactas, Físico-Químicas y Naturales, Universidad Nacional de Río Cuarto (UNRC). Ruta 36 km 60 I (5800) Río Cuarto (Córdoba, Argentina). E-mail: jcocilovo@exa.unrc.edu.ar

Héctor H. Varela. ICBIA-CONICET, Departamento de Ciencias Naturales, Facultad de Ciencias Exactas, Físico-Químicas y Naturales, UNRC. Ruta 36 km 601 (5800) Río Cuarto (Córdoba, Argentina). E-mail: hvarela@exa.unrc.edu.ar

Silvia G. Valdano. ICBIA-CONICET, Departamento de Ciencias Naturales, Facultad de Ciencias Exactas, Físico-Químicas y Naturales, UNRC. Ruta 36 km 60I (5800) Río Cuarto (Córdoba, Argentina). E-mail: svaldano@exa.unrc.edu.ar
}

Intersecciones en Antropología 22(2), julio-diciembre: 157-168. 2021. ISSN-e 1850-373X

https://doi.org/10.37176/iea.22.2.2021.610

Facultad de Ciencias Sociales - UNICEN - Argentina 


\section{INTRODUCCIÓN}

El parentesco entre grupos humanos andinos es bilateral, y los individuos reconocen como parientes consanguíneos a los descendientes de sus ancestros paternos y maternos (Ortiz Rescaniere, 1989). Los modelos de residencia se pueden establecer sobre la base de matrimonios monógamos o polígamos, de descendencia paterna, materna o bilateral, y las reglas de residencia pueden ser patrilocales, matrilocales o neolocales. Si la pareja se establece en el hogar paterno, la residencia es patrilocal o virilocal; si es en el hogar materno, la residencia es matrilocal; y si la pareja se aloja en un nuevo lugar, se denomina neolocal. En particular, en grupos quechua y aymara el patrón de residencia es patrilocal (Oyarce y Del Popolo, 2009), y en los aymara del norte de Chile, la residencia matrimonial actual es patrilocal (Carrasco Gutiérrez y Gavilán Vega, 2014); aunque Dransart (2011, p. 127) explica que en Isluga, "la residencia después del matrimonio a menudo es virilocal", pero en tales casos, la esposa no pierde sus derechos en el manejo de los recursos y los descendientes heredan las propiedades por igual.

En el norte de Chile y el noroeste argentino, el estudio en grupos arcaicos tempranos hasta comunidades agroalfareras tardías (5240-450 AP) permitió determinar la prevalencia de una estrategia de supervivencia basada en un sistema de parentesco con un modelo de residencia matrilocal (Cocilovo et al., 2017, 2019a). Esta experiencia fue revisada explorando las bases de datos de seis localidades de Chile entre los períodos Arcaico y Tardío (Punta de Teatinos, El Cerrito, Caleta Huelén 42, Pisagua, Calama y San Pedro de Atacama), con lo cual se confirmó un patrón de residencia matrilocal en el que el componente femenino reveló un modelo dispersivo diferenciado, con mayor heterogeneidad entre localidades y con menos migrantes por generación comparado con el componente masculino, menos diferenciado y con una mayor actividad migratoria (Cocilovo et al., 2019b). Igualmente, en el período tardío del noroeste argentino, a partir de distintas tasas migratorias y del tamaño efectivo de ambos sexos, se determinaron patrones de residencia matrilocal y patrilocal (Cocilovo et al., 2019c).

La información disponible sobre el desarrollo cultural y la evolución de la población antigua en Arica fue el resultado de la investigación conjunta de la arqueología y la antropología biológica, lo que permitió reconstruir uno de los procesos locales más importantes del poblamiento del Área Andina Centro Sur. La arqueología reveló la ocupación del territorio entre el décimo y el noveno milenios AP (9760-7000 AP) (Standen y Santoro, 2004) y estableció distintos períodos y fases que explicaron el desarrollo de la sociedad y dos tradiciones culturales durante el Horizonte medio: una altiplánica, representada por los estilos Tiwanaku, Cabuza y Charcollo; y la otra, heredada del desarrollo formativo de los valles occidentales, caracterizada inicialmente por el estilo Maytas/Chiribaya, que determina el surgimiento de la Cultura Arica (Espoueys et al., 1995b). Los estudios bioantropológicos destacaron aspectos clave de la estructura y evolución de las comunidades locales. Por ejemplo, se estableció una correlación significativa entre la variación fenotípica (continua y discontinua) y distintas fases cronológicas, basada en el desarrollo de un proceso dispersivo regulado por la actividad migratoria (Cocilovo y Rothhammer, 1996, 1999), el impacto de eventos colonizadores de grupos pescadores costeros y pastores-agricultores en el valle (Cocilovo et al., 2001) y el desarrollo del parentesco (Cocilovo y Varela, 1998). El desarrollo de la población y sus distintos períodos marcaron el proceso evolutivo local durante la conquista y colonización del territorio y el aporte genético derivado de la interacción con regiones próximas del sur de Perú y Bolivia, sectores clave del Área Andina Centro Sur (Rothhammer et al., 2003; Varela et al., 2013, 2014).

El análisis de la estructura de la población basado en la genética cuantitativa reveló la existencia de un mayor flujo migratorio externo en el valle con relación a la costa (Varela y Cocilovo, 2002), evidencias que se reafirmaron con base en el estadístico Fst entre los períodos Arcaico tardío (Morro Uhle y Morro 1-1/6), Formativo de la costa (Playa Miller 7) y Formativo del valle (Alto Ramírez) (Varela et al., 2004, 2006). Estudios posteriores revelaron relaciones entre el valle de Azapa, San Pedro de Atacama y los valles de Cochabamba (Varela et al., 2013, 2014), en coincidencia con la propuesta de las relaciones entre Moquegua y Cochabamba y su impacto "en poblaciones marginales, como las de Chile, fueron puentes de comunicación y dispersión cultural del núcleo altiplánico" (Uribe y Agüero, 2001, p. 421).

En los grupos chiribaya de Ilo Tumilaca/Cabuza (1178-600 AP) de la costa sur de Perú, el análisis de rasgos craneales y mandibulares comprobó que los varones eran fenotípicamente más variables y más 
móviles que las mujeres, lo que indica un patrón de residencia matrilocal (Nystrom y Malcom, 2010), evidencia que posteriormente se repitió en seis localidades de Chile (Punta de Teatinos, El Cerrito, Caleta Huelén 42, Pisagua, Calama y San Pedro de Atacama), al revelar un patrón de residencia similar (Cocilovo et al., 2019b).

La población antigua de la costa y el valle de Azapa en Arica brinda una oportunidad única para analizar las relaciones sociales y establecer el tipo de patrón de residencia posmarital y su evolución, sustentada por el desarrollo y adaptación de la población local a los cambios producidos en un marco cronológico aproximado de 5000 años.

\section{MATERIAL Y MÉTODOS}

El presente estudio se desarrolló con la información de una base de datos integrada por 305 individuos de ambos sexos y 29 variables craneométricas (Tabla 1), definidas por la Convención Internacional de Mónaco (en Comas, 1966) y Wilder (1920). La asignación de fechados, sitios y cronología sigue la síntesis contenida en Espoueys et al. (1995b). El material empleado se conserva en el Museo Nacional de Historia Natural de Santiago (MNHN) y en el Museo de Arqueología San Miguel de Azapa de Chile (MASMA), y corresponde a diferentes sitios ubicados en la costa y en el valle de Azapa, de los períodos Arcaico tardío (Morro de Arica Uhle, Morro 1 y Morro 1-6), Intermedio temprano (PIm7, Az14, Az22, Az70 y Az115), Medio (Az3, Az13 y Az103), Intermedio tardío (Plm3, Plm4, Az8, Az71, Az75, Az79, Az 105, Llu12 y Chll5) y Tardío (Plm4, Az8 y Llu13) (Figura 1).

El registro abarca desde el período Arcaico tardío 5240-3254 AP (Vera, 1981; Allison et al., 1984; Focacci y Chacón, 1989; Standen, 1991; Arriaza, 1994; Costa-Junqueira et al., 1999; Costa et al., 2000; Arriaza et al., 2001; Standen, 2003; Standen et al., 2004; Muñoz Ovalle, 2011), período Intermedio temprano o Formativo 2950-1450 AP (Muñoz Ovalle y Chacama, 2012), período Medio 1050-850 AP (Schiappacasse et al., 1991; Muñoz Ovalle, 2019), período Intermedio tardío 950-550 AP (Schiappacasse et al., 1991; Chacama, 2005) y Tardío ca. 500-450 AP (Santoro et al., 2004; Muñoz

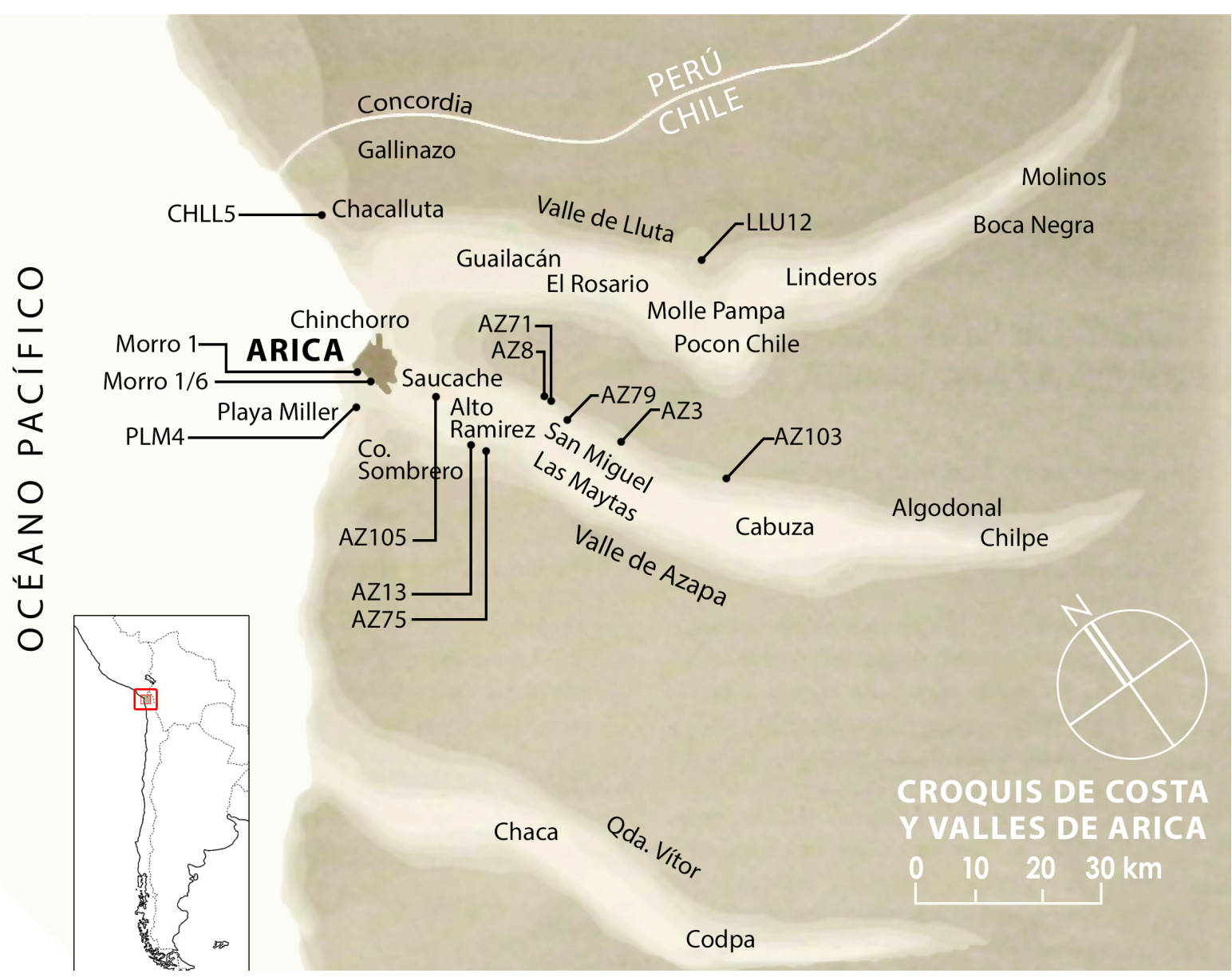

Figura 1: Mapa de la costa y valles de Arica con los principales sitios arqueológicos mencionados en el texto (modificado a partir de Espoueys et al., 1995a). 


\begin{tabular}{|l|l|l|}
\hline Longitud máxima & Diámetro alvéolo-basilar & Longitud del paladar \\
\hline Anchura máxima & Altura nasio-alveolar & Anchura del paladar \\
\hline Altura basilo-bregmática & Altura de la nariz & Altura órbito alveolar \\
\hline Altura porio-bregmática & Anchura de la nariz & Longitud foramen magnun \\
\hline Diámetro frontal mínimo & Altura del pómulo & Anchura foramen magnun \\
\hline Diámetro frontal máximo & Anchura biorbitaria & Curva nasion-bregma \\
\hline Anchura fronto-malar & Anchura de la órbita & Curva bregma-lambda \\
\hline Anchura bicigomática & Altura de la órbita & Curva lambda-opistion \\
\hline Anchura bimaxilar máxima & Anchura maxilo-alveolar & Curva horizontal \\
\hline Diámetro nasio-basilar & Longitud maxilo-alveolar & \\
\hline
\end{tabular}

de la información proporcionada por rasgos cuantitativos y marcadores genéticos y, de acuerdo con von CramonTaubadel (2014), los datos craneométricos pueden usarse de manera confiable para estudiar la historia de poblaciones

Tabla 1. Variables fenotípicas. Denominación.

Ovalle, 2019).

Las determinaciones del sexo y de la edad se realizaron de acuerdo con Genovés (1962), Bass (1981), Buikstra y Ubelaker (1994, pp. 32-38, 4753), y las relativas a la deformación artificial, de acuerdo con Dembo e Imbelloni (1938). Para las mediciones de las variables se utilizaron instrumentos originales de Siber y Hegner (Suiza). La distribución de los datos se controló mediante la estadística $\chi^{2}$ y se evaluaron las diferencias fenotípicas empleando métodos estadísticos de análisis multivariado de la varianza (MANOVA) y análisis discriminante (Seber, 1984) para los diseños basados en la evaluación entre períodos y sexos. Todos los análisis mencionados en este trabajo se realizaron con los residuos de la variación producida por la deformación artificial (Varela et al., 1993).

La magnitud de la diferenciación genética para rasgos cuantitativos se evaluó por el estadístico Fst de acuerdo con Relethford (1994, 1996, 2002), Relethford y Blangero (1990), Relethford y Harpending (1994) y Relethford et al. (1997). El estadístico Fst permite determinar la diferenciación genética por medio de la relación entre la varianza promedio dentro y entre grupos, de acuerdo con el modelo esperado del balance entre la deriva y la migración en ausencia de mutación y selección, aunque es relativamente insensible a la influencia de estos factores (Slatkin, 1994). Si bien no puede descartarse el efecto de la selección (Pérez y Monteiro, 2009), la mayor parte de la variabilidad observada entre poblaciones del Área Andina Centro Sur que mantuvieron una interacción regional y extrarregional puede explicarse por el efecto de la migración y la deriva (Varela et al., 2012).

Relethford (1994) demostró la comparabilidad dispersión y afinidades entre poblaciones. El estadístico Fst se calculó con una heredabilidad $\left(\mathrm{h}^{2}\right)$ de 0,55, un valor aceptable según Relethford (1994) y Relethford y Harpending (1994), y por los resultados de la experiencia previa en poblaciones locales sobre la variación genética máxima de los rasgos cuantitativos según Falconer y Mackay (1996) evaluada en bases de datos semejantes (Varela y Cocilovo, 1999, 2002, 2007; Medeot et al., 2008). Los cálculos se realizaron con el programa RMET (Relethford y Blangero, 1990).

El flujo genético regional y el proveniente de una fuente externa a la región se calcularon a partir de la proporción migratoria por generación, según el desarrollo original de Sewall Wright: $\mathrm{Nm}=$ $1 / 4 *[(1 / F s t)-1]$ (Falconer y Mackay, 1996). El patrón de residencia se determinó a partir de la relación (1-Fst $\widehat{o} / 1-F s t$ ㅇ), que expresa el cociente de las varianzas dentro de grupos entre individuos masculinos y femeninos. Se infiere un patrón de residencia matrilocal si la varianza masculina dentro de

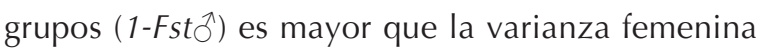
(1-Fsto ); si el valor masculino es menor, se infiere un patrón de residencia patrilocal; y es ambilocal si las varianzas entre ambos sexos son semejantes, es decir, la relación entre las varianzas masculinas/ femeninas debe ser igual a 1 si los sexos tienen la misma movilidad, más de 1 si los varones son más móviles o menos de 1 si lo son las mujeres (Konigsberg, 1988). Se utilizó una prueba de comparación entre dos coeficientes de correlación para evaluar si los coeficientes masculinos y femeninos son diferentes. Igualmente, dichos patrones pueden determinarse por la relación de las proporciones migratorias de los sexos $(\mathrm{Nm} \hat{\delta} / \mathrm{Nm}$ q). El presente estudio incluye el análisis para los siguientes diseños: 1) entre períodos (Arcaico tardío, Intermedio temprano, Medio, Intermedio tardío y Tardío); 2) entre períodos y áreas (costa, valle); 3) entre períodos 
y sexos; 4) entre períodos de la costa y sexos; y 5) entre períodos del valle y sexos.

\section{RESULTADOS}

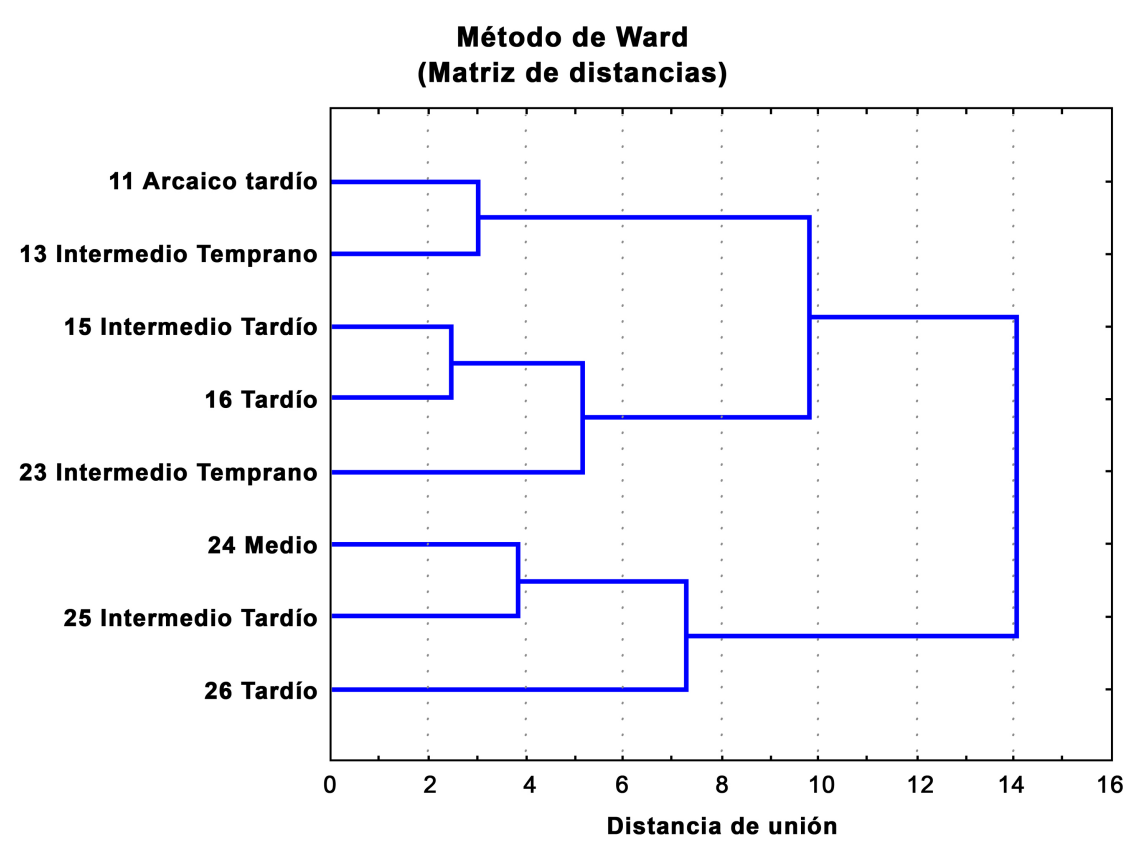

Figura 2. Distribución de los períodos en la costa y en el valle por valores $D^{2}$ de Mahalanobis y la técnica de clasificación de Ward. Identificación de los períodos en la costa: Arcaico tardío (11), Intermedio temprano (13), Intermedio tardío (15), Tardío (16); y en el valle: Intermedio temprano (23), Medio (24), Intermedio tardío (25) y Tardío (26). Lambda de Wilks $=0,157$ aprox. $F_{(203,1847)}=2,84, p<0,001$.

\begin{tabular}{|c|c|c|c|}
\hline \multirow{2}{*}{ Regiones } & \multicolumn{2}{|c|}{ Sexos } & \multirow{2}{*}{} \\
\cline { 2 - 3 } & Masculinos & Femeninos & Total \\
\hline Costa & $95(49,2)$ & $98(50,8)$ & 193 \\
\hline Valle & $58(51,8)$ & $54(48,2)$ & 112 \\
\hline Total & $\mathbf{1 5 3 ( 5 0 , 2 )}$ & $\mathbf{1 5 2}(\mathbf{4 9 , 8 )}$ & $\mathbf{3 0 5}$ \\
\hline
\end{tabular}

Nota: $\square 2=0,186, g l=1, p=0,666$ (porcentajes por fila entre paréntesis).

Tabla 2. Distribución de los sexos por regiones.

\begin{tabular}{|l|c|c|c|}
\hline \multirow{2}{*}{ Períodos } & \multicolumn{2}{|c|}{ Sexos } & \multirow{2}{*}{ Total } \\
\cline { 2 - 3 } & Masculinos & Femeninos & 99 \\
\hline Arcaico tardío & $49(49,5)$ & $50(50,5)$ & 99 \\
\hline $\begin{array}{l}\text { Intermedio } \\
\text { temprano }\end{array}$ & $42(49,4)$ & $43(50,6)$ & 85 \\
\hline Medio & $7(50,0)$ & $7(50,0)$ & 14 \\
\hline Intermedio tardío & $45(52,9)$ & $40(47,1)$ & 85 \\
\hline Tardío & $10(45,5)$ & $12(54,5)$ & 22 \\
\hline Total & $\mathbf{1 5 3 ( 5 0 , 2 )}$ & $\mathbf{1 5 2}(\mathbf{4 9 , 8 )}$ & $\mathbf{3 0 5}$ \\
\hline
\end{tabular}

Nota: $\square 2=0,494, g l=4, p=0,974$ (porcentajes por fila entre paréntesis).

Tabla 3. Distribución de los sexos por períodos.
En la distribución de los sexos por áreas no se observaron diferencias significativas (Chicuadrado $=0,186, g l=1, p=0,666)$ y tampoco por períodos (Chi-cuadrado $=0,494, g l=4, p=0,974$ ) (Tablas 2 y 3 ). En el dendrograma de la Figura 2 se representan las relaciones morfológicas entre los períodos para la costa y el valle de acuerdo con los valores $D^{2}$ de Mahalanobis tomando ambos sexos conjuntamente (valores $F$ con $g l=29$ y 267 , todos significativos, a excepción de los agrupamientos Intermedio tardío-Tardío, tanto en la costa como en el valle, y del agrupamiento Medio-Intermedio Tardío en el valle). La evaluación de las diferencias entre períodos y sexos destaca una diferencia global significativa entre períodos (Lambda de Wilks $=0,325$, aprox. $F_{(116,1083)}=$ $3,054, p<0,001)$, así como entre períodos y regiones (Lambda de Wilks =0,157, aprox. $F_{(203,1847)}=2,840, p<$ $0,001)$; mientras que para los individuos masculinos y femeninos se obtuvieron respectivamente los siguientes valores: Lambda de Wilks $=0,217$, aprox. $F_{(116,479)}=1,939, p<0,001$ y Lambda de Wilks $=0,190$, aprox. $F_{(116,475)}=2,125$, $p<0,001$. En el componente masculino se determinó una menor variación fenotípica entre períodos, en relación con el grupo femenino (Tabla 4).

En la Tabla 5 se presentan los resultados de la divergencia fenotípica sobre la base del estadístico Fst, su error estándar, la proporción migratoria $(\mathrm{Nm})$

\begin{tabular}{|l|l|c|c|c|}
\hline Entre & $\begin{array}{l}\text { Lambda } \\
\text { de Wilks }\end{array}$ & \multicolumn{1}{|c|}{$\boldsymbol{g}$} & $\begin{array}{c}\text { aprox. } \\
\boldsymbol{F}\end{array}$ & $\boldsymbol{p}$ \\
\hline Períodos & 0,325 & 116 y 1083 & 3,054 & $<0,001$ \\
\hline $\begin{array}{l}\text { Regiones- } \\
\text { Períodos }\end{array}$ & 0,157 & 203 y 1847 & 2,840 & $<0,001$ \\
\hline $\begin{array}{l}\text { Masculinos- } \\
\text { Períodos }\end{array}$ & 0,217 & 116 y 479 & 1,939 & $<0,001$ \\
\hline $\begin{array}{l}\text { Femeninos- } \\
\text { Períodos }\end{array}$ & 0,190 & 116 y 475 & 2,125 & $<0,001$ \\
\hline
\end{tabular}

Nota: gl: grados de libertad, $p$ : valor de probabilidad.

Tabla 4. Evaluación de las diferencias entre períodos, regiones y sexos. 


\begin{tabular}{|llllll|}
\hline & Fst & e.e. & Nm & $\begin{array}{l}\left(\mathbf{1 - F s t}{ }^{\lambda}\right) \\
(\mathbf{1 - F s t}+)\end{array}$ & $\begin{array}{l}\text { Patrón de } \\
\text { residencia }\end{array}$ \\
\hline Períodos & 0,042 & 0,005 & 5,7 & & \\
\hline Períodos-regiones & 0,060 & 0,005 & 3,9 & & \\
\hline Periodos-sexos & 0,044 & 0,006 & 5,4 & & \\
Masculinos & 0,054 & 0,008 & 4,3 & 1,001 & Bilocal \\
Femeninos & 0,055 & 0,008 & 4,3 & & \\
\hline Costa-sexos & 0,063 & 0,007 & 3,7 & & \\
Masculinos & 0,081 & 0,012 & 2,8 & 1,021 & Bilocal \\
Femeninos & 0,100 & 0,011 & 2,2 & & \\
\hline Valle-sexos & 0,081 & 0,010 & 2,8 & & \\
Masculinos & 0,106 & 0,013 & 2,1 & 1,025 \\
Femeninos & 0,128 & 0,015 & 1,7 & & Bilocal \\
\hline
\end{tabular}

Nota: e.e: error estándar, $N m$ : migrantes por generación.

Tabla 5. Valores Fst, error estándar, migrantes por generación, cociente entre varianzas dentro de subpoblaciones entre masculinos y femeninos, y patrón de residencia.

de cada caso y el patrón de residencia probable. Entre períodos se determinaron valores de Fst $=0,042 \pm 0,005$ y de $N m=5,7$; entre los periodos de la costa y el valle se registraron los valores Fst $=0,060 \pm 0,005$ y de $\mathrm{Nm}=3,9$, y al considerar los sexos se obtuvieron Fst $=0,044 \pm 0,006$ y $N m=5,4$. Para masculinos y entre períodos se estimó el valor $F s t=0,054 \pm 0,008$ $(\mathrm{Nm}=4,3)$, mientras que para femeninos y entre períodos los valores fueron $F s t=0,055 \pm 0,008(\mathrm{Nm}=4,3)$. En este caso, se reveló una movilidad migratoria similar en ambos sexos, es decir, un patrón de residencia bilocal, ya que $(1-0,054) /(1-$ $0,055) \approx 1,001 \quad(p \approx 1)$.

En los períodos de la costa se determinaron los valores $F s t=0,063 \pm 0,007$ $(\mathrm{Nm}=3,7)$, para masculinos $F_{s t}=0,081 \pm 0,012(\mathrm{Nm}=2,8)$; y para femeninos, Fst $=0,100 \pm 0,011(\mathrm{Nm}=2,2)$, que evidencian una movilidad migratoria similar en ambos sexos (1-0,081)/ $(1-0,100) \approx 1,021 \quad(p=0,426)$. En los períodos del valle se obtuvieron los valores $F_{s t}=0,081 \pm 0,010$ y $\mathrm{Nm}=2,8$, para masculinos $F s t=0,106 \pm 0,013$ y $N m=2,1$; y para femeninos, Fst $=0,128 \pm 0,015$ y $\mathrm{Nm}=1,7$, con una movilidad migratoria semejante para ambos sexos $(1-0,106) /$ $(1-0,128) \approx 1,025(p=0,6486)$. En ambos casos, se reveló un patrón de residencia bilocal, reflejado equivalentemente en las relaciones de números de migrantes por generación, pues los migrantes masculinos son similares a los femeninos en la costa ( 2,8 y 2,2 respectivamente) y en el valle $(2,1$ y 1,7 respectivamente) (Tabla 5).

En las Figuras 3, 4 y 5 se consignan las estructuras de los períodos en general y de los períodos según los sexos de acuerdo con la varianza fenotípica observada (rombos) y esperada (cuadrados) con respecto a los valores $r_{i i}$ de la distancia al centroide de la distribución. En la Figura 3 se presenta la distribución por períodos, donde se manifiesta una mayor actividad migratoria durante el Intermedio temprano; en el Intermedio tardío se da una mayor actividad local y la influencia

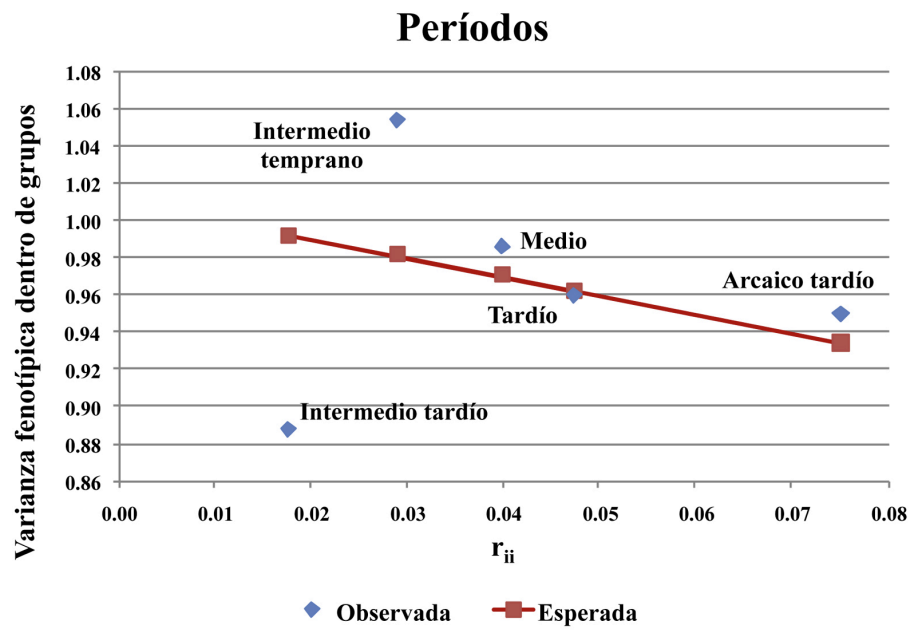

Figura 3. Distribución de la varianza fenotípica observada (rombos) y esperada (cuadrados) entre los períodos Arcaico tardío, Intermedio temprano, Medio, Intermedio tardío y Tardío. Valores rii: distancia al centroide de la distribución (valor $F s t=0,042 \pm 0,005, N m=5,7$ ).

\section{Períodos - sexo masculino}

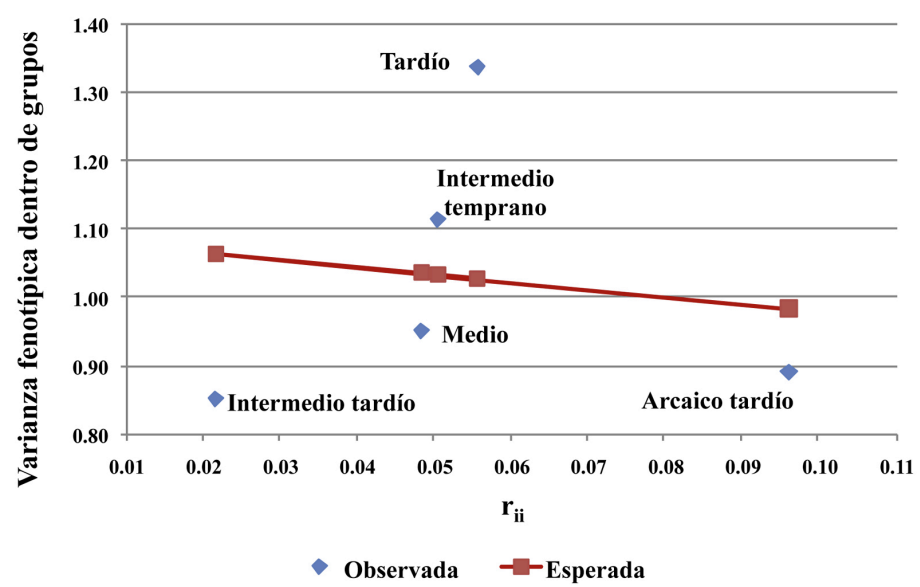

Figura 4. Distribución de la varianza fenotípica observada (rombos) y esperada (cuadrados) del sexo masculino entre los períodos Arcaico tardío, Intermedio temprano, Medio, Intermedio tardío y Tardío. Valores rii: distancia al centroide de la distribución (valor $F s t=0,054 \pm 0,008$, $\mathrm{Nm}=4,3)$. 
Períodos - sexo femenino

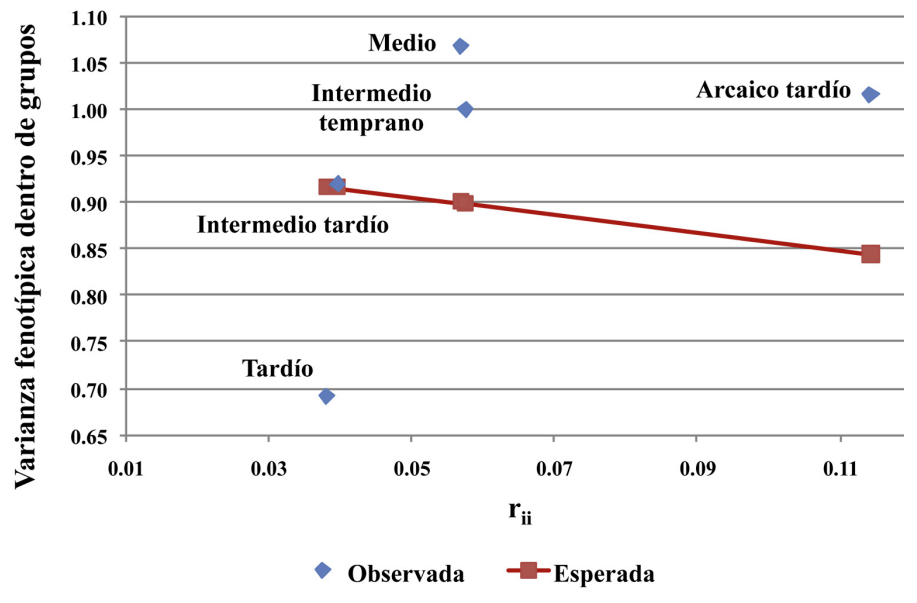

Figura 5. Distribución de la varianza fenotípica observada (rombos) y esperada (cuadrados) del sexo femenino entre los períodos Arcaico tardío, Intermedio temprano, Medio, Intermedio tardío y Tardío. Valores rii: distancia al centroide de la distribución (valor Fst $=0,055 \pm 0,008$, $\mathrm{Nm}=4,3)$.

de la deriva genética; y para el resto de los períodos (Arcaico, Medio y Tardío), se observa una proximidad al equilibrio entre deriva genética y flujo génico. En el componente masculino (Figura 4), durante los períodos Intermedio temprano y Tardío, se destacó un efecto migratorio externo y/o un mayor tamaño efectivo (mayor hibridez) desde un amplio rango geográfico, y en los períodos Arcaico tardío, Medio e Intermedio tardío, una mayor interacción local revela el efecto de la deriva génica. En el grupo femenino (Figura 5), durante los períodos Arcaico tardío, Intermedio temprano y Medio, se comprobó una mayor actividad migratoria externa. En el período Tardío dominó el efecto de la deriva genética y una mayor actividad entre localidades próximas, mientras que en el período Intermedio tardío predominó el equilibrio entre migración externa y deriva génica.

\section{DISCUSIÓN Y CONCLUSIONES}

La composición de la muestra reveló una distribución equilibrada de los períodos de acuerdo con su clasificación en la costa y en el valle (Espoueys et al., 1995c), y la distribución de la base de datos para ambos sexos (Tablas 2 y 3) garantizó la robustez de los resultados del análisis estadístico realizado entre períodos, entre costa-valle y entre sexos (Figura 2 y Tabla 4).

El análisis realizado sobre la base del estadístico Fst (Tabla 5) reveló un patrón de residencia bilocal entre períodos; también en la costa y en el valle las tendencias destacaron un patrón de residencia bilocal, en ambos casos con una actividad migratoria masculina similar a la femenina.

La evaluación general entre períodos reveló una destacada actividad migratoria en el Intermedio temprano, en los períodos Medio, Tardío y Arcaico tardío se observó una proximidad al equilibrio entre deriva genética y migración, mientras que la deriva genética dominó en el Intermedio tardío (Figura 3). En el componente masculino (Figura 4) fue mayor la actividad migratoria durante los períodos Intermedio temprano y en particular en el Tardío, mientras que en los períodos Medio, Arcaico tardío y principalmente Intermedio tardío influyeron el efecto de la deriva genética y una mayor actividad local. En el conjunto femenino (Figura 5) se observó un mayor aporte migratorio extrarregional durante los períodos Arcaico tardío, Intermedio temprano y Medio; en el período Intermedio tardío se comprueba un equilibrio entre flujo génico externo a la región y deriva genética, mientras que en el período Tardío se destacó el efecto de la deriva genética.

El proceso del arribo y asentamiento de los primeros grupos arcaicos en el espacio territorial y la posterior interacción con otros grupos determinó la estructura fenotípica local, cuya evidencia se destaca por las diferencias estadísticas entre períodos, la actividad migratoria y el efecto de la deriva genética, que reflejan el desarrollo de las relaciones de parentesco que configuraron la estructura local de la población, incluyendo el aporte migratorio extrarregional durante cinco milenios de evolución.

La investigación arqueológica consigna la influencia de poblaciones altiplánicas durante el segundo milenio a. C. que interactuaron con el período Arcaico tardío y contribuyeron con el desarrollo del período Intermedio temprano o Formativo de Arica (Muñoz Ovalle, 1982, 2011; Ayala, 2001). En el estudio de la textilería de Arica se destaca una Tradición de Tierras Altas con las tecnologías de la subárea valluna (Cochabamba, Omereque, Mojocoya), que se asocian a la cerámica Charcollo, Cabuza y Tiwanaku durante el Formativo tardío, período Medio, parte del Intermedio tardío y en el período Medio del Altiplano Meridional y Circunlacustre, y una tradición textil de Valles Occidentales asociada a Maytas, con relaciones estilísticas de los valles bajos del sur peruano (Agüero, 2000). Se ha sugerido que Moquegua y 
Cochabamba habrían tenido un mayor impacto en poblaciones marginales como las de Chile, al convertirse en puentes de comunicación y dispersión cultural del núcleo altiplánico (Uribe y Agüero, 2001), por medio de la iconografía, alfarería y textilería de Tiwanaku durante el período Medio (Uribe y Agüero, 2004). Del mismo modo, a partir del estudio de rasgos craneométricos, se revelaron relaciones de amplio rango entre Cochabamba durante los períodos Formativo y Tiwanaku y los períodos Formativo y Tardío del Valle de Azapa y San Pedro de Atacama Tardío (Varela et al., 2013, 2014).

La supervivencia de los grupos que habitaron la costa de Arica estuvo más asociada con el aprovechamiento de los recursos del mar (pesca, recolección y caza), mientras que los que se desarrollaron en el interior del valle de Azapa dependían principalmente de la agricultura. De todos modos, existió desde épocas tempranas una interacción entre las distintas regiones del área andina centro sur que incluía la actividad trashumante y caravanera con el tráfico de mercancías y el tránsito de personas, principalmente masculinas, a lo largo de una compleja red de caminos y rutas que conectaban localidades y regiones del Perú, Bolivia, norte de Chile y noroeste de Argentina hasta tiempos históricos (Tarragó, 1977, 1984; Llagostera, 1995; Núñez y Dillehay, 1995; Nielsen, 2002, 2011; Montenegro y Ruiz, 2007; De Nigris, 2009; Molina Otárola, 2011; Yacobaccio, 2012; Cocilovo et al., 2017).

Los valores Fst entre períodos revelaron que la divergencia genética femenina es algo mayor que la masculina y que, tanto en la costa como en el valle, el número de migrantes por generación es menor en las mujeres respecto a los varones, lo cual podría sugerir una mayor movilidad masculina y un patrón de residencia matrilocal. Resultados similares se obtuvieron en trabajos realizados en diferentes regiones y períodos del Área Andina Centro Meridional (Cocilovo et al., 2017, 2019a, b, c); sin embargo, las diferencias encontradas son pequeñas y estadísticamente no significativas, por lo que el patrón de residencia puede considerarse bilocal.

Los estudios genéticos en poblaciones nativas de América del Sur y del Área Andina Centro Sur seguramente pueden ser una importante fuente de información para aportar al análisis de los patrones de residencia posmarital, mediante la estimación de la divergencia genética masculina y femenina empleando marcadores genéticos autosómicos y de herencia uniparental (ADNmt y ADN del cromosoma Y). Por ejemplo, Fuselli et al. (2003) estimaron una diferenciación genética similar en ambos sexos (Фst-cromosomaY $=0,17$ y $\Phi$ st- $A D N m t=0,16)$ en poblaciones nativas de Sudamérica, mientras que Cabana et al. (2014) analizaron poblaciones de los Andes centrales de Perú y obtuvieron valores de 0,41 para Фst-cromosomaY y de 0,19 para ФstADNmt respectivamente, lo que indica una mayor diferenciación genética masculina con respecto a la femenina. Estos resultados sugieren que en el primer caso se infiere una movilidad similar en ambos sexos y un modelo de residencia posmarital bilocal, mientras que el segundo caso se relaciona con una mayor movilidad femenina que masculina y un patrón de residencia posmarital patrilocal.

Etcheverría Turres (1998) y Dransart (2011) observan que la residencia en comunidades aymara de pastores de Isluga y Cariquima (norte de Chile) después del matrimonio suele ser virilocal o patrilocal, pero en estos casos, la esposa no pierde sus derechos a pastorear sus animales y los de su marido e hijos en el bofedal de su comunidad de origen. Ortiz Rescaniere (1989) expresa que en los grupos en los cuales el pastoreo es importante, la residencia idealmente es por el lado del padre, pero en la práctica, la unidad doméstica se pliega por el lado más conveniente según sus actividades de agricultura y pastoreo. Esta última idea se ajusta mejor a los resultados logrados en esta presente experiencia para la población de Arica, así como los obtenidos en otras poblaciones antiguas del Área Andina Centro Meridional (Cocilovo et al., 2017, 2019a, b, c), es decir, que las parejas parecen establecerse en el hogar materno o paterno y mantienen un modelo de residencia más flexible o conveniente como el bilocal.

Se concluye que a partir de la reconstrucción del proceso evolutivo de Arica fue posible evaluar los patrones de residencia, las relaciones de parentesco y su impacto en la composición genética local que contribuyeron al desarrollo de la población.

\section{Agradecimientos}

El presente trabajo se realizó con fondos del Consejo Nacional de Investigaciones Científicas y Técnicas (PIP No 112-201701-00288) y la Secretaría de Ciencia y Técnica, Universidad Nacional de Río Cuarto (SeCyT-UNRC, Res. CS N 161/16 y $N^{\circ}$ 1038/18). También expresamos nuestro 
agradecimiento a los revisores por las sugerencias recibidas, las que contribuyeron a su mejoramiento.

\section{REFERENCIAS CITADAS}

Agüero, C. (2000). Las tradiciones de tierras altas y de valles occidentales en la textilería arqueológica del Valle de Azapa. Chungara, Revista de Antropología Chilena, 32(2), 217-225.

Allison, M., Focacci, G., Arriaza, B., Standen, V., Rivera, M. y Lowenstein, J. (1984). Chinchorro, momias de preparación complicada. Chungara, Revista de Antropología Chilena, 13, 155-174.

Arriaza, B. T. (1994). Tipología de las momias chinchorro y la evolución de las prácticas de momificación. Chungara, Revista de Antropología a Chilena, 26(1), 11-47.

Arriaza, B. T., Standen, V. G., Belmonte, E., Neils, F. y Rosello, E. (2001). The peopling of the Arica coast during the preceramic: a preliminary view. Chungara, Revista de Antropología Chilena, 33(1), 31-36.

Ayala, P. (2001). Las sociedades formativas del Altiplano Circumtiticaca y Meridional y su relación con el Norte Grande de Chile. Estudios Atacameños, 21, 7-39.

Bass, W. M. (1981). Human osteology: a laboratory and field manual of the human skeleton. University of Missouri.

Buikstra, J. E. y Ubelaker, D. H. (1994). Standards for Data Collection from Human Skeletal Remains. Arkansas Archaeological Survey Research Series. No. 44.

Cabana, G. S., Lewis, C. M. Jr., Tito, R. Y., Covey, R. A., Cáceres, A. M., De La Cruz, A. F., ..., Stone, A. C. (2014). Population genetic structure of traditional populations in the Peruvian Central Andes and implications for South American population history. Human Biology, 86(3), 147-165.

Carrasco Gutiérrez, A. M. y Gavilán Vega, V. T. (2014). Género y etnicidad. Ser hombre y ser mujer entre los Aymara del Altiplano Chileno. Diálogo Andino, 45, 169-180.

Chacama, R. J. (2005). Patrón de asentamiento y uso del espacio. Precordillera de Arica, extremo norte de Chile, siglos X-XV. Bulletin de l'Institut français d'études andines, 34(3), 357-378.

Cocilovo, J. A. y Rothhammer, F. (1996). El valle de Azapa en el norte de Chile. Análisis de un modelo biocronológico para establecer la estructura de la población. Revista Argentina de Antropología Biológica, 1(1), 232-245.

Cocilovo, J. A. y Rothhammer, F. (1999). Microevolución morfológica y extinción del parentesco en asentamientos humanos prehistóricos del Valle de Azapa, Chile. Revista Chilena de Historia Natural, 72, 213-218.

Cocilovo, J. A. y Varela, H. H. (1998). Variación morfológica, estructura canónica y bioensayo de parentesco en poblaciones prehistóricas del Norte de Chile. Chungara, Revista de Antropología Chilena, 30(1), 75-85.

Cocilovo, J. A, Varela, H. H. y Valdano, S. G. (2017). South Central Andean Area. Social interaction, relationship and genetic divergence in the Atacama Desert. Journal of Anthropology and Archaeology, 5(2), $1-15$.

Cocilovo, J. A, Varela, H. H. y Valdano, S. G. (2019a). Residencia posmarital, movilidad y relaciones sociales en el Área Andina Centro-Sur. Latin American Antiquity, 30(3), 459-470. https://doi.org/10.1017/ $\underline{\text { laq. } 2019.23}$

Cocilovo, J. A, Varela, H. H. y Valdano, S. G. (2019b). Post-marital residence pattern in ancient populations of the North of Chile. Annals of Archaeology, 2(2), 1-10. https://www.sryahwapublications.com/annals-ofarchaeology/volume-2-issue-2/1.php

Cocilovo, J. A, Varela, H. H. y Valdano, S. G. (2019c). Migración y residencia posmarital en el Noroeste Argentino. Relaciones de la Sociedad Argentina de Antropología, 44(2), 233-250.

Cocilovo, J. A., Varela, H. H., Espoueys, O. y Standen, V. (2001). El proceso evolutivo de la población nativa antigua de Arica. Chungara, Revista de Antropología Chilena, 33(1), 13-20.

Comas, J. (1966). Manual de Antropología Física. Universidad Autónoma de México.

Costa-Junqueira, M. A., Quevedo, S., Cocilovo, J. A. y Llagostera, A. (1999). El hombre arcaico costero: su biodiversidad y bioadaptación. Informe final proyecto FONDECYT 1960169. MS.

Costa, M. A., Varela, H. H., Cocilovo, J. A., Quevedo, S. y Valdano, S. G. (2000). Perfil paleodemográfico de morro de Arica. Una población de pescadores arcaicos del Norte de Chile. Boletín del Museo Nacional de Historia Natural, 49, 215-235.

De Nigris, M. R. (2009). Arqueología, Minería y Metalurgia en la localidad de Cobres y sus alrededores (Períodos Prehispánico y Colonial) [tesis de licenciatura. Universidad Nacional de Salta].

Dembo, A. e Imbelloni, J. (1938). Deformaciones intencionales del cuerpo humano, Humanior, Sección A 3. Imprenta Luis L. Gotelli. 
Dransart, P. (2011). Social principles of Andean camelid pastoralism and archaeological interpretations. En U. Albarella y A. Trentacoste (Eds.), Ethnozoarchaeology: The present and past of human-animal relationships (pp. 123-130). Oxbow Books.

Espoueys, O., Horta, H. y Reciné, V. (1995a) Estudio de una pieza textil de filiación tiwanaku del Valle de Azapa, Arica, Chile. Boletín del Museo Chileno de Arte Precolombino, 6, 111-125.

Espoueys, O., Schiappacasse, V., Berenguer, J. y Uribe, M. (1995b). En torno al surgimiento de la Cultura Arica. Hombre y Desierto. Tomo 1, 171-184.

Espoueys, O., Uribe, M., Román, A. y Deza, A. (1995c). Fechados por termoluminiscencia para la cerámica del período Medio del Valle de Azapa (Primera parte). Actas del XIII Congreso Nacional de Arqueología Chilena. Hombre y Desierto, Tomo 2, 31-53.

Etcheverría Turres, C. (1998). División sexual del trabajo y matrimonio Aymara contemporáneo desde una perspectiva de género. Revista Ciencias Sociales, 8, 97-108.

Falconer, D. S. y Mackay, T. F. C. (1996). Introduction to Quantitative Genetics. Pearson Longman.

Focacci, G. y Chacon, S. (1989). Excavaciones arqueológicas en los faldeos del Morro de Arica, sitios $1 / 6$ y $2 / 2$. Chungara, Revista de Antropología Chilena, 22, 15-62.

Fuselli, S., Tarazona-Santos, E., Dupanloup, I., Soto, A., Luiselli, D. y Pettener, D. (2003). Mitochondrial DNA diversity in South America and the Genetic History of Andean Highlanders. Molecular Biology and Evolution, 20(10), 1682-1691.

Genovés, S. (1962). Introducción al diagnóstico de la edad y del sexo en restos óseos prehistóricos. Instituto de Historia.

Konigsberg, L. W. (1988). Migration models of prehistoric postmarital residence. American Journal of Physical Anthropology, 77, 471-482.

Llagostera, A. (1995). El componente Aguada en San Pedro de Atacama. Boletín del Museo Chileno de Arte Precolombino, 6, 9-34.

Medeot, E. A., Cocilovo, J. A. y Varela, H. H. (2008). Varianza ambiental y estabilidad del desarrollo en la población prehispánica de Las Pirguas (Salta, Argentina). Latin American Antiquity, 19(2), 146-157.

Molina Otárola, R. (2011). Los otros arrieros de los valles La Puna y el Desierto de Atacama. Chungara, Revista de Antropología Chilena, 43(2), 177-187.

Montenegro, M. y Ruiz, M. (2007). Tránsito y Paisaje en la Puna de Jujuy durante los Desarrollos Regionales: Una Aproximación Iconográfica. Cuadernos FHyCS-UNJu,
$32,167-185$.

Muñoz Ovalle, I. (1982). Las sociedades costeras en el litoral de Arica durante el período arcaico tardío y sus vinculaciones con la costa peruana. Chungara, Revista de Antropología Chilena, 9, 124-151.

Muñoz Ovalle, I. (2011). Persistencia de la tradición pescadora recolectora en la costa de Arica: Identificación de rasgos culturales y discusión sobre su alcance en el contexto de las poblaciones agrícolas tempranas. Chungara, Revista de Antropología Chilena, 43 Número Especial 1, 469-485.

Muñoz Ovalle, I. (2019). Cronología del periodo medio en el valle de Azapa, norte de Chile: estilos, fechados y contextos culturales del poblamiento humano. Chungara, Revista de Antropología Chilena, 51(4), 595-611.

Muñoz Ovalle, I. y Chacama, J. (2012). Transformación del paisaje social en Arica, norte de Chile: de pescadores arcaicos a agricultores incipientes. Estudios Atacameños, 44, 123-140.

Nielsen, A. E. (2002). Asentamientos, conflicto y cambio social en el altiplano de Lípez (Potosí). Revista Española de Antropología Americana, 32, 179-205.

Nielsen, A. E. (2011). El Tráfico de Caravanas entre Lípez y Atacama visto desde la Cordillera Occidental. En L. Núñez y A. E. Nielsen (Eds.), En Ruta: Arqueología Historia y Etnografía del Tráfico Sur Andino (pp. 83110). Encuentro Grupo Editor.

Núñez, L. y Dillehay, T. (1995). Movilidad giratoria, armonía social y desarrollo en los Andes Meridionales: Patrones de tráfico e interacción económica, 2. da ed., Universidad Católica del Norte.

Nystrom, K. C. y Malcom, C. M. (2010). Sex-specific phenotypic variability and social organization in the Chiribaya of Southern Peru. Latin American Antiquity, 21(4), 375-397. https://doi. org/10.7183/1045-6635.21.4.375

Ortiz Rescaniere, A. (1989). La comunidad, el parentesco y los patrones de crianza andinos. Anthropologica, 7(7), 135-170.

Oyarce, A. M. y Del Popolo, F. (2009). Hogar y familia indígenas en Bolivia, Chile y Panamá: Algunos hallazgos y su aporte a la recolección de la información censal. CEPAL, Notas de población, 87, 121-149.

Pérez, S. I. y Monteiro, L. R. (2009). Nonrandom factors in modern human morphological diversification: a study of craniofacial variation in southern south american populations. Evolution, 63-4, 978-993.

Relethford, J. H. (1994). Craniometric variation among 
modern human populations. American Journal of Physical Anthropology, 95(1), 53-62.

Relethford, J. H (1996). Genetic drift can obscure population history: Problem and solution. Human Biology, 68, 29-44.

Relethford, J. H. (2002). Apportionment of global human genetic diversity based on craniometrics and skin color. American Journal of Physical Anthropology, 118, 393-398.

Relethford, J. H. (2003). Programa RMET 5.0. http:// employees.oneonta.edu/relethjh/programs/

Relethford, J. H. y Blangero, J. (1990). Detection of differential gene flow patterns of quantitative variation. Human Biology, 62, 5-25.

Relethford, J. H. y Harpending, H. C. (1994). Craniometric variation, genetic theory and modern human origins. American Journal of Physical Anthropology, 95(3), 249-270.

Relethford, J. H., Crawford, M. H. y Blangero, J. (1997). Genetic drift and gene flow in post-famine Ireland. Human Biology, 69, 443-465.

Rothhammer, F., Moraga, M., Rivera, M., Santoro, C. M., Standen, V. G., García, F. y Carvallo, P. (2003). Análisis de ADNmt de restos esqueletales del sitio arqueológico de Tiwanaku y su relación con el origen de sus constructores. Chungara, Revista de Antropología Chilena, 35(2), 269-274.

Santoro, C. M., Romero, A., Standen, V. y Torres, A. (2004). Continuidad y cambio en las comunidades locales, períodos Intermedio Tardío y Tardío, Valles Occidentales del Área Centro Sur Andina. Chungara, Revista de Antropología Chilena Volumen Especial, Tomo 1, 235-247.

Schiappacasse, V., Román, A., Muñoz, I., Deza, A. y Focacci, G. (1991). Cronología por termoluminiscencia de la cerámica del extremo Norte de Chile: primera parte. En Actas XI Congreso Nacional de Arqueología Chilena 1, 43-60. Museo Nacional de Historia Natural.

Seber, G. A. F. (1984). Multivariate Observations. Wiley \& Sons.

Slatkin, M. (1994). Gene flow and population structure. En L. Real (Ed.), Ecological Genetics (pp. 3-17). Princeton University Press.

Standen, V. G. (1991). El cementerio Morro 1: nuevas evidencias de la tradición funeraria Chinchorro (período Arcaico, norte de Chile) [tesis de maestría. Universidad Católica de Lima].

Standen, V. G. (2003). Bienes funerarios del cementerio Chinchorro Morro 1: descripción, análisis e interpretación. Chungara, Revista de Antropología Chilena, 35(2), 175-207.
Standen, V. G. y Santoro, C. M. (2004). Patrón funerario arcaico temprano del sitio Acha-3 y su relación con Chinchorro: Cazadores, pescadores y recolectores de la costa norte de Chile. Latin American Antiquity, 15(1), 89-109. https://doi.org/10.2307/4141565

Standen, V. G., Santoro, C. M. y Arriaza, B. T. (2004). Síntesis y propuestas para el período Arcaico en la costa del extremo norte de Chile. Chungara, Revista de Antropología Chilena, Volumen Especial, 36, 201-212.

Tarragó, M. (1977). Relaciones prehispánicas entre San Pedro de Atacama Norte de Chile y regiones aledañas: la Quebrada de Humahuaca. Estudios Atacameños, 5, 50-63.

Tarragó, M. (1984). La historia de los pueblos circumpuneños en relación con el altiplano y los Andes Meridionales. Estudios Atacameños, 7, 93-104.

Uribe, M. y Agüero, C. (2001). Alfarería, textiles y la integración del Norte Grande de Chile a Tiwanaku. Boletín de Arqueología PUCP, 5, 397-426.

Uribe, M. y Agüero, C. (2004). Iconografía, alfarería y textilería Tiwanaku: elementos para una revisión del período Medio en el Norte Grande de Chile. Chungara, Revista de Antropología Chilena, Volumen Especial, 1055-1068.

Varela, H. H. y Cocilovo, J. A. (1999). Evaluation of the environmental component of the phenotypic variance in prehistoric population. Homo, 50, 46-53.

Varela, H. H. y Cocilovo, J. A. (2002). Genetic drift and gene flow in a prehistoric population of the Azapa valley and coast, Chile. American Journal of Physical Anthropology, 118, 259-267.

Varela, H. H. y Cocilovo, J. A. (2007). Phenotypic, maximum genetic and special environmental variability in prehistoric human populations. American Journal of Physical Anthropology, 132(1), 17-24.

Varela, H. H., Cocilovo, J. A. y O’Brien, T. G. (2012). Evolución de las Poblaciones Prehistóricas del Área Andina Centro Sur: Deriva Genética, Migración y Selección Natural. Antropo, 28, 9-22. http://www. didac.ehu.es/antropo/28/28-2/Varela.pdf

Varela, H. H., Cocilovo, J. A. y O'Brien, T. G. (2013). Valley to valley: the biological connection between prehispanic residents of Cochabamba, Bolivia, and Azapa, Chile. Advances in Anthropology, 3(4), 210215. http://dx.doi.org/10.4236/aa.2013.34030

Varela, H. H., Cocilovo, J. A. y Valdano, S. G. (1993). Evaluación de la influencia del efecto sexo, edad y deformación artificial en la estimación de distancias biológicas por medio de la $\mathrm{D}^{2}$ de Mahalanobis, Boletín de la Sociedad Española de Antropología Biológica, 14, 135-148. 
Varela, H. H., Cocilovo, J. A., Fuchs, M. L. y O’Brien, T. G. (2014). Coastal, valley, and oasis interaction: impact on the evolution of ancient populations in the South Central Andes. American Journal of Physical Anthropology, 155, 591-599.

Varela, H. H., Cocilovo, J. A., Quevedo, S. y Costa, M. (2004). La estructura de la población de pescadores del período Arcaico tardío y Formativo de Arica. Boletín del Museo Nacional de Historia Natural, 53, 149-160.

Varela, H. H., Cocilovo, J. A., Santoro, C. M. y Rothhammer, F. (2006). Microevolución de grupos humanos arcaicos de Arica, norte de Chile, y su contribución genética a las poblaciones del período Formativo. Revista Chilena de Historia Natural, 79,
185-193.

Vera, J. (1981). Momias Chinchorro de preparación complicada del Museo de Historia Natural de Valparaíso. Anales del Museo de Historia Natural de Valparaíso, 14, 5-18.

von Cramon-Taubadel, N. (2014). Evolutionary insights into global patterns of human cranial diversity: population history, climatic and dietary effects. Journal of Anthropological Sciences, 92, 43-77.

Wilder, H. H. (1920). Laboratory Manual of Anthropometry. P. Blakiston's.

Yacobaccio, H. D. (2012). Intercambio y Caravanas de Llamas en el Sur Andino 3000-1000 AP. Comechingonia Revista de Arqueología, 16, 31-51. 